\title{
Hydration and Packing are Crucial to Amyloidogenesis as Revealed by Pressure Studies on Transthyretin Variants that Either Protect or Worsen Amyloid Disease
}

\author{
Astria D. Ferrão-Gonzales ${ }^{1}$, Leonardo Palmieri', Marcelo Valory ${ }^{1}$ \\ Jerson L. Silva ${ }^{1}$, Hilal Lashuel ${ }^{2}$, Jeffery W. Kelly ${ }^{3}$ and Débora Foguel ${ }^{1 *}$
}

${ }^{1}$ Departamento de Bioquímica Médica, Instituto de Ciências Biomédicas, Universidade Federal do Rio de Janeiro CP 68041, Rio de Janeiro 21941-590, Brazil

${ }^{2}$ Center for Neurologic Diseases Brigham and Women's Hospital and Department of Neurology Harvard Medical School Boston, MA 02115, USA

${ }^{3}$ The Scripps Research Institute 10550 North Torrey Pine Rd MB 12, La Jolla, CA 92037 USA

\begin{abstract}
The formation of amyloid aggregates is the hallmark of the amyloidogenic diseases. Transthyretin (TTR) is involved in senile systemic amyloidosis (wild-type protein) and familial amyloidotic polyneuropathy (point mutants). Through the use of high hydrostatic pressure (HHP), we compare the stability among wild-type (wt) TTR, two disease-associated mutations (V30M and L55P) and a trans-suppressor mutation (T119M). Our data show that the amyloidogenic conformation, easily populated in the disease-associated mutant L55P, can be induced by a cycle of compression-decompression with the wt protein rendering the latter highly amyloidogenic. After decompression, the recovered wt structure has weaker subunit interactions (loosened tetramer, $\mathrm{T}_{4}^{*}$ ) and presents a stability similar to L55P, suggesting that HHP induces a defective fold in the wt protein, converting it to an altered conformation already present in the aggressive mutant, L55P. On the other hand, glucose, a chemical chaperone, can mimic the trans-suppression mutation by stabilizing the native state and by decreasing the amyloidogenic potential of the $\mathrm{wt}$ TTR at $\mathrm{pH}$ 5.0. The sequence of pressure stability observed was: L55P $<$ V30M $<$ wt $\ll$ T119M. The pressure dissociation of L55P at $1{ }^{\circ} \mathrm{C}$ exhibited dependence on protein concentration, allowing us to assess the volume change of association and the free-energy change. After a cycle of compression-decompression at $37^{\circ} \mathrm{C}$ and $\mathrm{pH} 5.6$ or lower, all amyloidogenic variants underwent aggregation. Binding of bis-(8-anilinonaphthalene-1-sulfonate) (bis-ANS) revealed that the species formed under pressure retained part of its tertiary contacts (except T119M). However, at neutral $\mathrm{pH}$, where aggregation did not take place after decompression, bis-ANS binding was absent. Thus, TTR has to experience this partially folded conformation to undergo aggregation after decompression. Overall, our studies provide evidence that amyloidogenesis correlates with less packed structures (larger volume changes) and high susceptibility to water infiltration. The hydration effects can be counteracted by osmolytes or by a specific mutation.
\end{abstract}

(C) 2003 Elsevier Science Ltd. All rights reserved

Keywords: transthyretin; amyloid; thermodynamic stability; packing defects; high hydrostatic pressure

\section{Introduction}

Abbreviations used: bis-ANS, bis-(8-anilinonaphthalene-1-sulfonate); TTR, transthyretin; HHP, high hydrostatic pressure; $L S$, light-scattering.

E-mail address of the corresponding author: foguel@bioqmed.ufrj.br
Protein misfolding has been implicated in a number of diseases such as Alzheimer's disease, Parkinson's disease, transmissible spongiform encephalopathies, Huntington's disease, familial amyloidotic polyneuropathy, cystic fibrosis, type II 
diabetes, and a number of other well-known diseases. ${ }^{1-4}$ The deposition of insoluble amyloid fibrils is a characteristic of the pathogenesis of most of these diseases, but relatively little is known about the mechanisms that underlie fibrillogenesis. ${ }^{1}$ Transthyretin (TTR) is a tetrameric protein composed of identical 127 residue subunits having predominantly a $\beta$-sheet structure..$^{5,6}$ The eight strands present in TTR are organized into two $\beta$-sheets (DAGH and CBEF). TTR is found in human plasma $(0.1-0.4 \mathrm{mg} / \mathrm{ml})$ and cerebral spinal fluid $(0.017 \mathrm{mg} / \mathrm{ml})$. The plasma form serves as a secondary carrier for thyroxine and for binding retinol-binding protein. ${ }^{7,8}$ Wild-type (wt) TTR is responsible for senile systemic amyloidosis, a disease that affects $25 \%$ of people over 80 years old, and is characterized by heavy amyloid deposits in the heart. ${ }^{9}$ On the other hand, more than 80 point mutants of TTR have been described thus far, most of them involved in familial amyloidotic polyneuropathy. ${ }^{10}$ In general, familial amyloidotic polyneuropathy patients present the first symptoms by the second or third decade with peripheral neuropathy, cardiomyopathy, carpal tunnel syndrome, and vitreous opacities. ${ }^{11}$

Among the described mutants of TTR, V30M and L55P are the most important because of a high frequency of occurrence and aggressiveness of the symptoms evoked, respectively. On the other hand, the non-amyloidogenic mutant T119M has been described as an interallelic trans-suppressor variant in compound heterozygotes that alleviates the aggressiveness of V30M disease. ${ }^{12-14}$

Although the resolution of the crystal structure of several amyloidogenic mutants has not shown significant differences from the wt protein, ${ }^{15,16}$ several other studies have focused on the mechanisms that could explain their higher propensity to undergo aggregation. ${ }^{17-20}$ It is now well accepted that an amyloidogenic intermediate with an altered conformation occurs prior to fibril formation. TTR mutants are more easily denatured by low $\mathrm{pH}$ when compared to the wt protein. ${ }^{19,21}$ Although this lower stability of the mutant proteins can explain their higher tendency to aggregate, acidic $\mathrm{pH}$ by itself induces aggregation of the aggressive mutant and the wt protein.

The oligomeric state of the amyloidogenic intermediate is still under debate. ${ }^{22-24}$ The acid-induced denaturation experiments have suggested a monomer as precursor for fibrillogenesis, while recent evidence obtained by the use of high hydrostatic pressure (HHP) pointed to the possible participation of an altered tetramer in equilibrium with monomers as the raw material for fibril formation in senile systemic amyloidosis. ${ }^{22}$ Recently, the crystal structure of the highly amyloidogenic triple mutant G53S/E54D/L55S at $2.3 \AA$ resolution revealed that it is a tetramer. ${ }^{25}$ Other evidence for the possible participation of an oligomeric species (either a dimer or a multiple of it) as the building block for TTR aggregation comes from the studies performed by Serag and co-workers, where cysteine substitution mutants were employed. ${ }^{23}$ However, there is equally compelling evidence against the participation of a dimeric intermediate in amyloidosis. ${ }^{26}$ Deciphering whether a monomeric or an oligomeric intermediate is the key intermediate is complicated by the fact that these intermediates are in equilibrium with each other.

HHP has been used successfully to denature and dissociate proteins, protein-DNA complexes and virus particles. ${ }^{27,28} \mathrm{~A}$ unique property of pressureinduced denaturation is the formation of partially folded or molten-globule states at equilibrium, reported in several cases. ${ }^{28}$ In the last three years the use of HHP has been expanded and large protein aggregates have been studied successfully by this methodology. ${ }^{29-32}$ In addition, we have shown recently that after a cycle of compressiondecompression, wt TTR formed fibrils under mild conditions $\left(\mathrm{pH} 5-5.6,37^{\circ} \mathrm{C}\right)$. At $0{ }^{\circ} \mathrm{C}$, the main quaternary structure recovered was tetrameric TTR, and the tetramers were less stable than the native, non-pressurized TTR. This altered tetramer is called $\mathrm{T}_{4}^{*}$ and is thought to represent a preaggregate state of TTR. ${ }^{22}$ More recently, Niraula and co-workers described a decrease in thermodynamic stability of $\mathrm{V} 30 \mathrm{M}$ in relation to the wt protein at neutral $\mathrm{pH}^{33}$

In the present study, we compare the stability against pressure of wt TTR to variants (T119M, L55P and V30M). Unlike the wt protein, L55P presents concentration-dependence in the pressure curves, which allows us to calculate the volume and free-energy changes of association. After a cycle of compression-decompression at $37^{\circ} \mathrm{C}$, the amyloidogenic variants aggregate into amyloid fibrils. Under pressure at acidic pH, L55P, V30M and wt proteins bind bis-(8-anilinonaphthalene-1sulfonate) (bis-ANS), suggesting the formation of a partially folded state. The compression curve displayed by L55P resembles the decompression curve of the wt protein, indicating that HHP treatment tends to convert the wt TTR into an "L55Plike" protein. Less packing and higher susceptibility to infiltration by water can explain both the lower pressure stability and higher amyloidogenicity of L55P. Perturbation of the hydration effects by osmolytes renders the wt protein more stable and less amyloidogenic upon pressure release.

\section{Results and Discussion}

\section{Comparing the thermodynamic stability of wt and variants of TTR at $1^{\circ} \mathrm{C}$ and at $37^{\circ} \mathrm{C}$ by the use of HHP}

Figures 1 and 2 show the effects of HHP at $\mathrm{pH}$ 7.5 on wt, L55P, V30M and T119M at $1{ }^{\circ} \mathrm{C}$ (Figure 1) and at $37^{\circ} \mathrm{C}$ (Figure 2). The average energy of tryptophan emission (center of spectral mass) was used as a sensor of the conformational changes induced by HHP (Figures 1(A) and 2(A)). The 


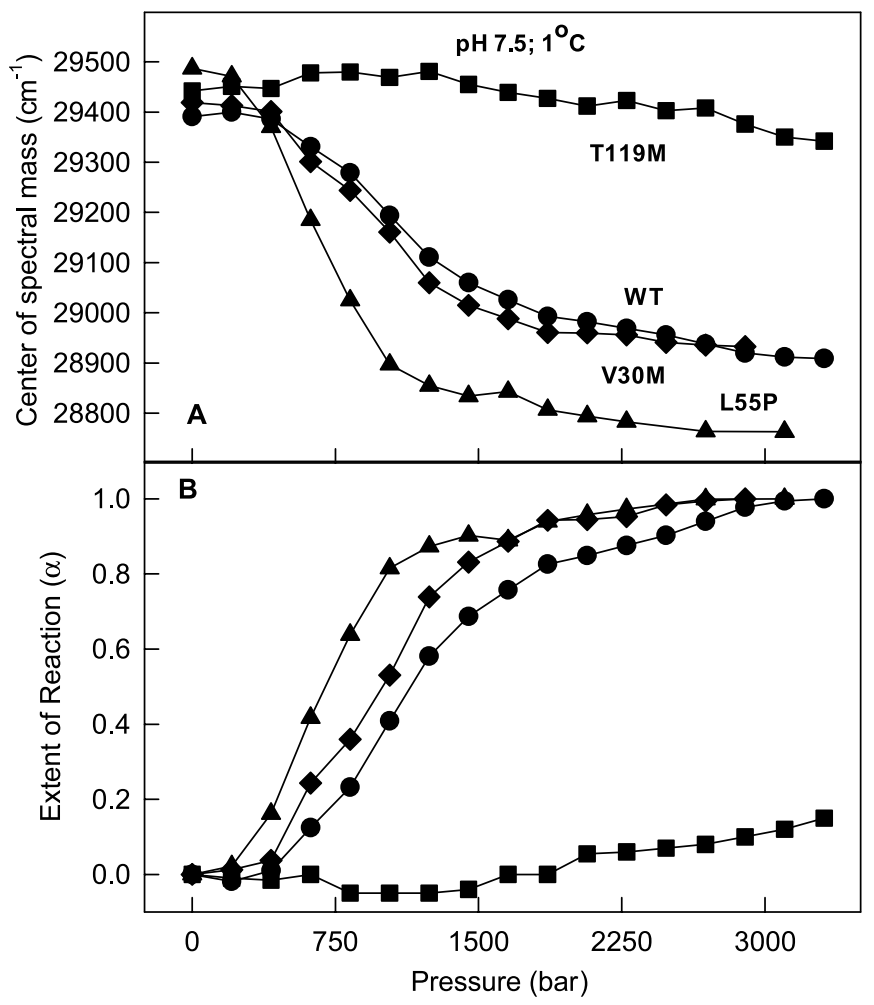

Figure 1. Dissociation-denaturation of TTR variants under pressure at $1{ }^{\circ} \mathrm{C}$. (A) The center of spectral mass of tryptophan was followed as a function of pressure at $\mathrm{pH} 7.5$.

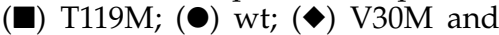
(A) L55P. (B) Extent of reaction $(\alpha)$ as a function of pressure calculated from equation (2) using the curves presented in A. Protein concentration was $1 \mu \mathrm{M}$ in all cases. Excitation was set at $280 \mathrm{~nm}$ and emission collected from $300 \mathrm{~nm}$ to $400 \mathrm{~nm}$.

extent of reaction $(\alpha)$ was calculated according to equation (2) and plotted in Figures 1(B) and 2(B). At $1{ }^{\circ} \mathrm{C}, \mathrm{L} 55 \mathrm{P}$ was the most labile variant (Figure 1(B), triangles) followed by V30M (diamonds), wt (circles) and T119M (squares). The mutant T119M was not dissociated by pressure even at $1^{\circ} \mathrm{C}$. In Figure 2, the experiments were performed at $37^{\circ} \mathrm{C}$ and the same sequence of stability was observed: $\mathrm{L} 55 \mathrm{P}<\mathrm{V} 30 \mathrm{M}<\mathrm{wtPPP} \angle \mathrm{T} 119 \mathrm{M}$. It is worth emphasizing that at $37^{\circ} \mathrm{C}$ the stability of V30M against pressure was more closely related to that of L55P, while at $1{ }^{\circ} \mathrm{C}$ its stability resembled that of the wt protein (Figures 1(B) and 2(B) and see the $p_{1 / 2}$ values presented in Table 1$)$. The L55P and

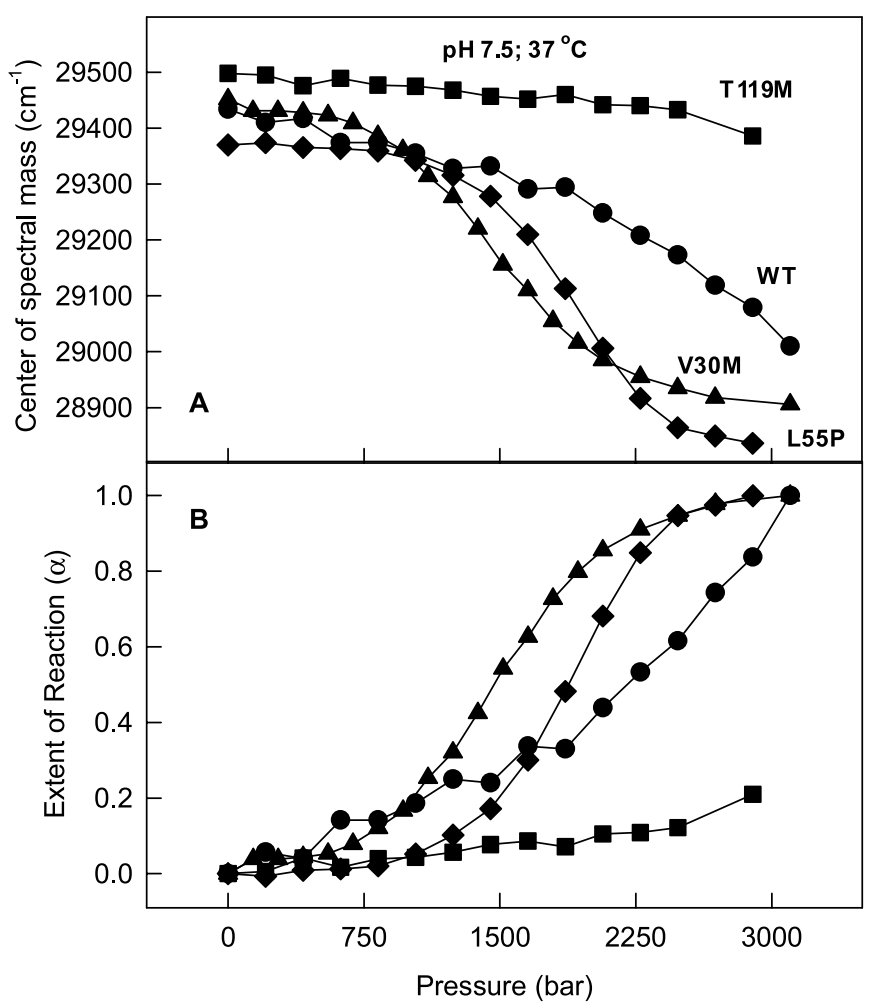

Figure 2. Dissociation-denaturation of TTR variants under pressure at $37^{\circ} \mathrm{C}$. (A) The center of spectral mass of tryptophan was followed as a function of pressure at $\mathrm{pH} 7.5$. (ם) T119M; (•) wt; (•) V30M and $(\Delta)$ L55P. (B) Extent of reaction $(\alpha)$ as a function of pressure calculated from equation (2) using the curves presented in A. Other conditions as in Figure 1. 
Table 1. Spectroscopic properties of wt and mutants of TTR at pH 7.5

\begin{tabular}{lccccc}
\hline & $\begin{array}{c}\text { Center of mass initial } \\
\left(\mathrm{cm}^{-1} \mathrm{~nm}^{-1}\right) 1^{\circ} \mathrm{C}\end{array}$ & $\begin{array}{c}\text { Center of mass final } \\
\left(\mathrm{cm}^{-1} \mathrm{~nm}^{-1}\right) 1^{\circ} \mathrm{C}\end{array}$ & $\begin{array}{c}p_{1 / 2} \\
(\mathrm{bar}) 1{ }^{\circ} \mathrm{C}\end{array}$ & $\begin{array}{c}\text { Center of mass initial } \\
\left(\mathrm{cm}^{-1} \mathrm{~nm}^{-1}\right) 37^{\circ} \mathrm{C}\end{array}$ & $\begin{array}{c}\text { Center of mass final } \\
\left(\mathrm{cm}^{-1} \mathrm{~nm}^{-1}\right) 37^{\circ} \mathrm{C}\end{array}$ \\
\hline WT & $29,390 / 340$ & $28,900 / 346$ & 1,150 & $29,430 / 340$ & $\begin{array}{c}p_{1 / 2} \\
\left(\mathrm{bar}^{\circ} 37^{\circ} \mathrm{C}\right.\end{array}$ \\
L55P & $29,450 / 340$ & $28,800 / 347$ & 690 & $29,450 / 340$ & $29,000 / 345$ \\
V30M & $29,420 / 340$ & $28,930 / 346$ & 980 & $29,370 / 340$ & $28,900 / 346$ \\
T119M & $29,440 / 340$ & $29,340 / 341$ & - & $29,500 / 339$ & $28,840 / 347$ \\
\hline
\end{tabular}

$p_{1 / 2}=$ pressure where the extent of reaction is $50 \%$.

V30M variants were shown to be more susceptible to acid denaturation than the wt protein. ${ }^{19}$

Table 1 summarizes the spectroscopic properties of TTR variants and the $p_{1 / 2}$ values obtained at $1{ }^{\circ} \mathrm{C}$ and at $37^{\circ} \mathrm{C}$. The comparison of $p_{1 / 2}$ values at these two temperatures shows the higher sensi-
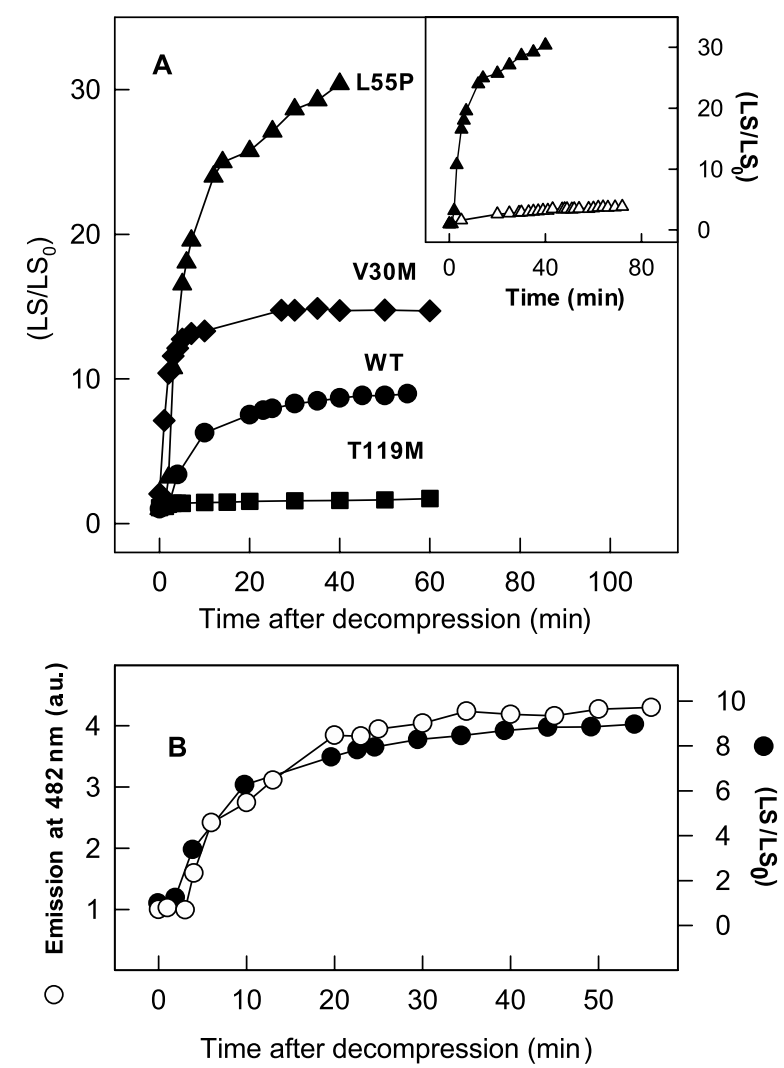

Figure 3. HHP induces fibril formation after decompression. (A) The proteins were subjected to $3 \mathrm{kbar}$ during $\sim 60$ minutes at $37^{\circ} \mathrm{C}$. After pressure release, the light-scattering $(L S)$ was measured and normalized to the initial value $\left(L S / L S_{0}\right)$. Conditions: $(\boldsymbol{\square}) \mathrm{T} 119 \mathrm{M}, 5 \mu \mathrm{M}$, $\mathrm{pH} 3.7 ;(\bullet) \mathrm{wt},(\bullet) \mathrm{V} 30 \mathrm{M}$ and $(\mathbf{\Delta}) \mathrm{L} 55 \mathrm{P}$ were at $1 \mu \mathrm{M}$ and $\mathrm{pH}$ 5.6. Inset: L55P $(1 \mu \mathrm{M})$ was incubated at $\mathrm{pH} 5.6$ at atmospheric pressure and $L S$ was recorded $(\triangle)$. For comparison, the curve obtained after pressure release from A is presented ( $\mathbf{\Delta})$. (B) wt TTR was compressed in the presence of $5 \mu \mathrm{M}$ thioflavin. After pressure release, fluorescence intensity at $482 \mathrm{~nm}$ was recorded $(O)$. The data are plotted together with the LS increase obtained simultaneously $(\bullet)$. The LS was measured by exciting the samples at $320 \mathrm{~nm}$ and collecting the emission from $315 \mathrm{~nm}$ to $325 \mathrm{~nm}$. The areas under the spectra were used to evaluate the extent of aggregation. tivity of the denaturation of TTR to low temperature, which confirms the crucial role of hydrophobic interactions in maintaining the native, tetrameric structure of TTR.

Recently, Schneider and co-workers ${ }^{34}$ observed that subunit exchange of wt TTR was more pronounced at $4{ }^{\circ} \mathrm{C}$ than at $37^{\circ} \mathrm{C}$, in agreement with the lower tetramer stability at low temperatures reported here. The hydrophobic interactions are evident in the crystal structure of TTR, where they contribute to the edge-to-edge and face-to-face dimer interface. ${ }^{6}$ It is convenient to investigate the folding mechanism of TTR at low temperatures, since aggregation can be avoided.

We note that the initial center of spectral mass values recovered completely after decompression (see Figure 5(B), broken line as an example) for all proteins. In size-exclusion chromatography, all proteins were recovered nearly completely as tetramers after decompression (not shown).

\section{Pressure-induced aggregation of TTR variants}

After a cycle of compression-decompression at $37^{\circ} \mathrm{C}$ and $\mathrm{pH} 5.6$, wt TTR undergoes aggregation forming amyloid fibrils. ${ }^{22}$ To investigate whether pressure could induce fibril formation in the variants of TTR, the proteins were incubated at $\mathrm{pH}$ 5.6 under 3000 bar $\left(1 \mathrm{bar}=10^{5} \mathrm{~Pa}\right)$ for 60 minutes at $37^{\circ} \mathrm{C}$. This incubation time is enough to shift the tryptophan emission completely to the red. After this time, pressure was released and the light scattering $(L S)$ was monitored at atmospheric pressure (Figure 3(A)). The increases in $L S$ were very pronounced and fast for L55P, intermediate for V30M and $w t$, and absent for T119M. The inset shows for comparison a control experiment where the L55P was incubated at pH 5.6, always at atmospheric pressure (open triangles). As expected, a slow, spontaneous fibrillogenesis is observed at this $\mathrm{pH}$, causing a fourfold increase in LS. However, the extent of aggregation of L55P after decompression was significantly higher, suggesting a massive formation of fibrils after pressure treatment (filled triangles). Figure 3(B) shows a similar experiment where thioflavin emission was used as an indicator of fibril formation. In this case, wt TTR was used. These data suggest that pressure treatment forms fibrils that bind thioflavin $\mathrm{T}$.

From these experiments, we can conclude that there is also an inverse correlation between 


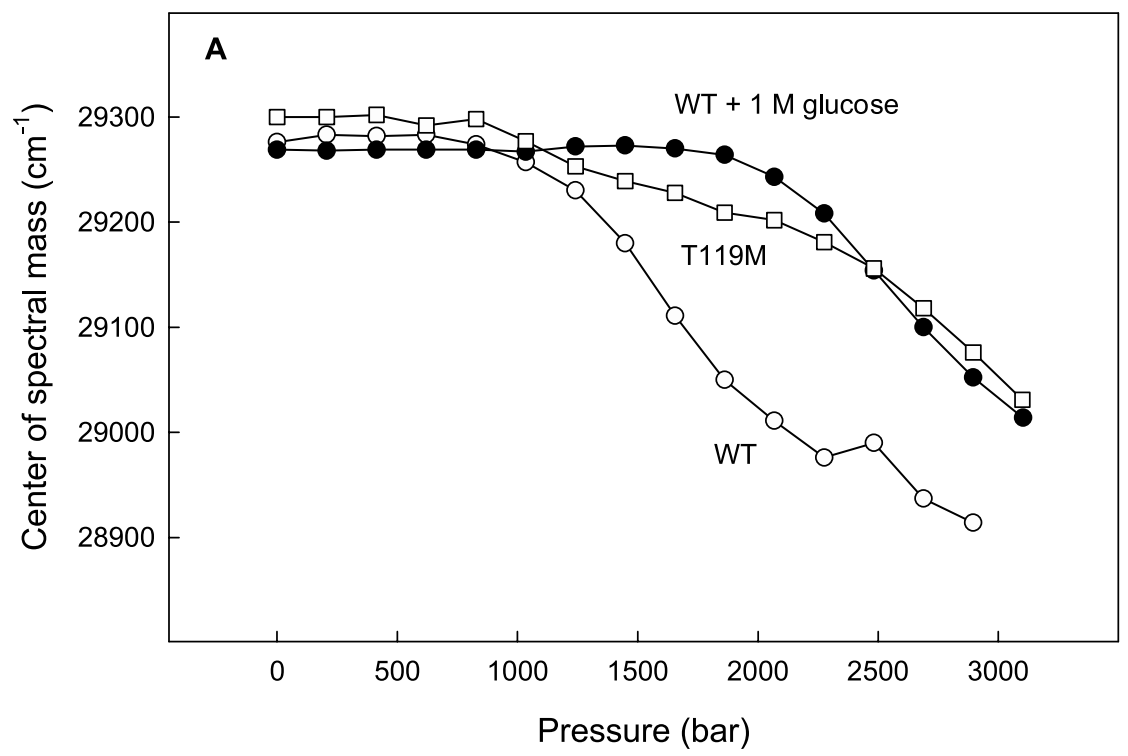

Figure 4. Protective effects of

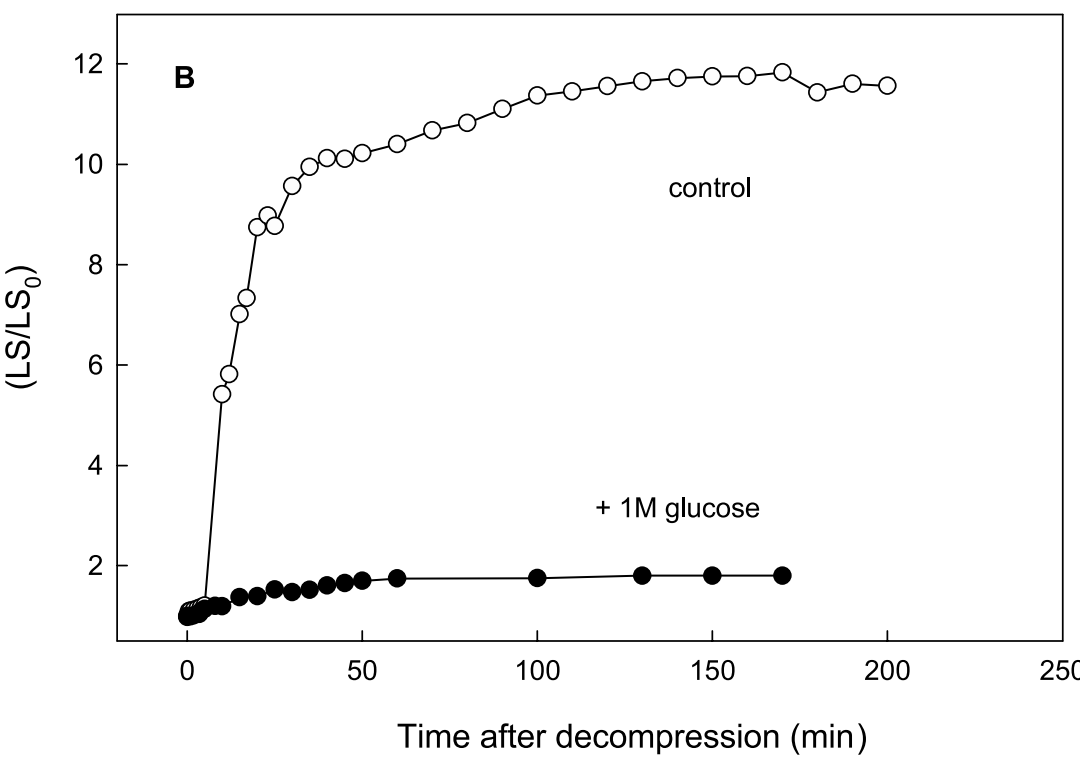
$1 \mathrm{M}$ glucose on the pressureinduced dissociation-denaturation (A) or aggregation (B) of $\mathrm{wt}$ TTR. In (A), at $\mathrm{pH} 5.0,37^{\circ} \mathrm{C}$, $1 \mu \mathrm{M}$ wt TTR was compressed in the absence $(O)$ or in the presence of $1 \mathrm{M}$ glucose $(\bullet)$ and the center of spectral mass of tryptophan was followed as a function of pressure. For comparison, the compression curve of $\mathrm{T} 119 \mathrm{M}$ is displayed at $\mathrm{pH} 3.7 ; 37^{\circ} \mathrm{C}(\square)$. In (B), at $\mathrm{pH} 5.0,37^{\circ} \mathrm{C}, 3.5 \mu \mathrm{M}$ wt TTR was subjected to $3 \mathrm{kbar}$ during $\sim 60$ minutes in the absence $(O)$ or in the presence of $1 \mathrm{M}$ glucose $(\bullet)$. After pressure release, the light-scattering ( $L S)$ was measured and normalized to the initial value $\left(L S / L S_{0}\right)$. Other conditions were as described for Figures 1 and 3.

stability against HHP and amiloidogenicity: the higher the stability, the lower the aggregation after pressure treatment.

\section{Inhibition of pressure-induced amyloidogenesis by glucose}

Experimental and theoretical approaches indicate that the underlying mechanism of pressure unfolding is the penetration of water into the protein matrix. ${ }^{35-37}$ The stabilizing effect of cosolvents such as sugars, polyols or methylamines on the denaturation process has been studied extensively and the most accepted interpretation for this stabilization is the preferential exclusion of such cosolutes from the protein domains (preferential hydration), which shifts the equilibrium towards the native state. ${ }^{38}$ Recent reports have addressed the effects of different cosolvents on the aggregation. ${ }^{39,40}$

Here, we investigate the effects of $1 \mathrm{M}$ glucose (Figure 4) on the pressure-induced denaturation (Figure $4(\mathrm{~A})$ ) or on the aggregation (Figure $4(\mathrm{~B})$ ) of wt TTR. As seen, glucose exerts a protective effect on the denaturation of wt TTR at $\mathrm{pH} 5.0$ and $37^{\circ} \mathrm{C}$ as followed by the center of spectral mass change (Figure $4(\mathrm{~A})$ ). The $p_{1 / 2}$ value increases $\sim 1000$ bar in the presence of glucose. Interestingly, when present under aggregating conditions, glucose inhibits almost completely the aggregation of wt TTR after pressure release (Figure 4(B)). The effects of glucose were concentration-dependent and another sugar, sucrose, had similar effects (not shown).

These data suggest that glucose stabilizes a native, fibril-incompetent species be it either the native tetramer or the native monomer. In Figure 

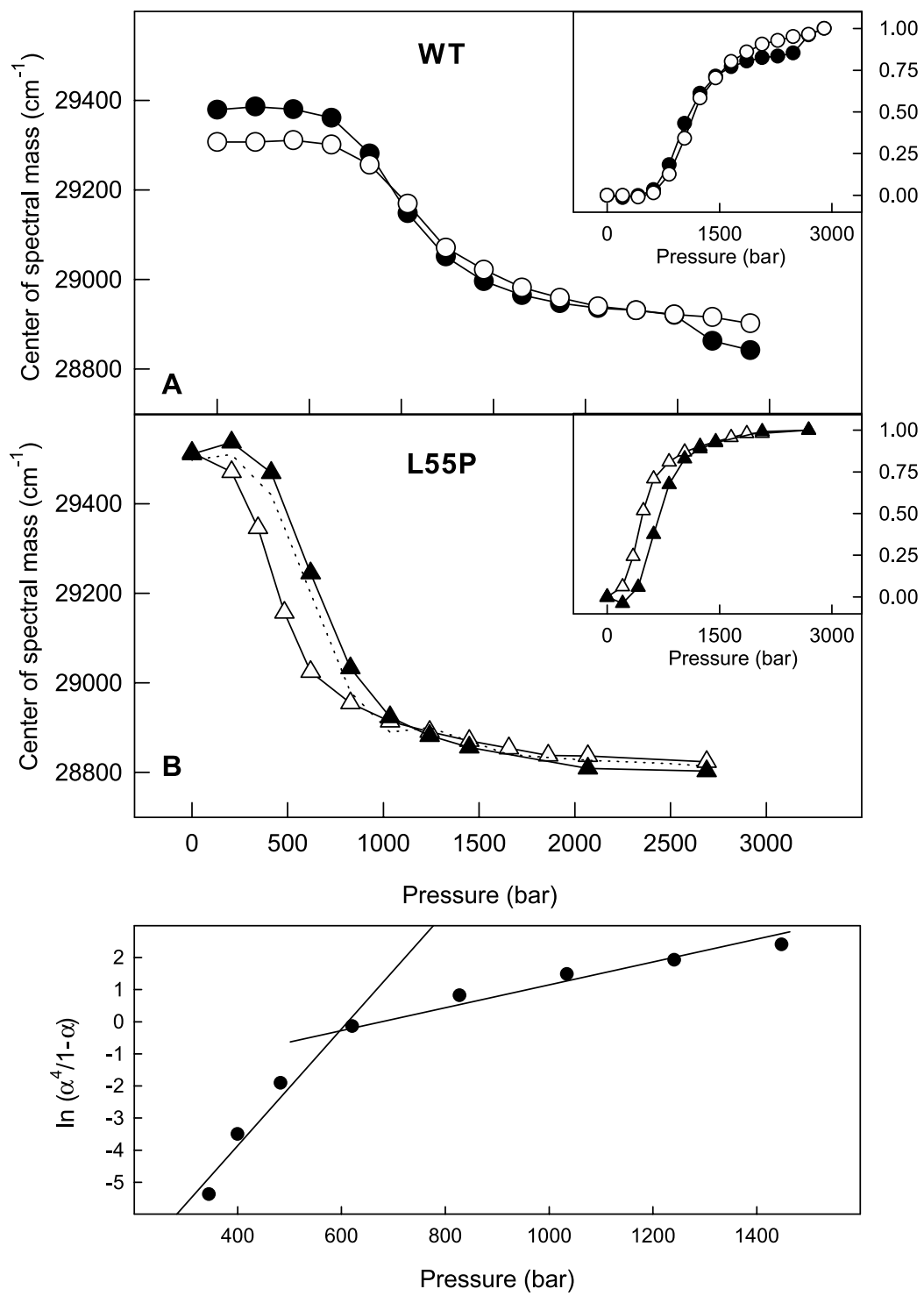

Figure 5. Concentration-dependence of the pressure-induced effects on TTR at $\mathrm{pH} 7.5,1{ }^{\circ} \mathrm{C}$. (A) wt protein at $(\bigcirc) 1$ or $(\bullet) 10 \mu \mathrm{M}$ and (B) L55P at $(\triangle) 0.5$ or $(\mathbf{\Lambda})$ $3.5 \mu \mathrm{M}$. The broken line represents the decompression curve at $3.5 \mu \mathrm{M}$. Insets: Extent of reaction $(\alpha)$ as a function of pressure for the concentrations mentioned before. (C) Plot of $\ln \left(\alpha^{4} / 1-\alpha\right)$ versus pressure for L55P calculated from the curve presented in B $(0.5 \mu \mathrm{M})$. The symbols represent the average of three measurements and the error is smaller than the symbol size. Other conditions are as described for Figure 1.

4(A), the pressure-denaturation curve of T119M at $\mathrm{pH} 3.7,37^{\circ} \mathrm{C}$ in the absence of any cosolvent is included for comparison. At this extreme $\mathrm{pH}$ value, T119M is still a tetramer and non-amyloidogenic as shown by MacCutchen and collaborators. ${ }^{41}$ Even at this low $\mathrm{pH}$, after pressure release, aggregation of T119M was not noticed (Figure 3, squares) even by turbidimetry. Interestingly, the wt protein in the presence of glucose became "less-amyloidogenic" (Figure 4(B)). These results suggest that glucose mimics the effects of the trans-suppressor mutation rendering the wt TTR more stable and less amyloidogenic.

\section{Concentration-dependence of the pressure- induced dissociation of L55P}

Dissociation of oligomeric proteins is expected to be accompanied by dependence on protein concentration under equilibrium conditions. ${ }^{28,42}$ However, several large oligomers do not obey this rule precisely; their anomalous behavior has been attributed to the existence of conformational heterogeneity among the individual subunits. ${ }^{42,43}$

Figure 5 shows the changes in the center of spectral mass as a function of pressure for wt TTR (A) and L55P (B) at two different concentrations of protein. The experiments were performed at $1{ }^{\circ} \mathrm{C}$ and at pH 7.5 to avoid aggregation. Clearly, there was a lack of concentration-dependence in the dissociation of wt TTR but not in the L55P mutant (insets).

Since the dissociation of L55P was accompanied by concentration-dependence, absence of hysteresis and complete reversibility of the center of spectral mass value (Figure 5(B), broken line), we were able to calculate the volume change and free-energy change of association from equation (3). The plot $\ln \left(\left(\alpha^{4}\right) /(1-\alpha)\right)$ versus pressure (Figure 5(C)) presented two well-defined transitions. In fact the two transitions can be seen in the inset of Figure 5(B), where concentrationdependence is very clear in the first one (from 1 bar to 600 bar) but absent from the second 
(above 600 bar). This observation suggests that the first transition is related to a process with order higher than 1 (likely tetramer to monomer dissociation), whereas the second transition would represent the denaturation of the separated monomers.

The calculated volume change of association for the tetramer-monomer equilibrium extracted from the first transition was equal to $430( \pm 30) \mathrm{ml} / \mathrm{mol}$. The dissociation constant and free energy change of association at $1{ }^{\circ} \mathrm{C}$ were $1.2 \times 10^{-21} \mathrm{M}^{-3}$ and $-26.25 \mathrm{kcal} / \mathrm{mol}$, respectively $(1 \mathrm{cal}=4.184 \mathrm{~J})$. We note that the slope of the second transition is much smaller (about sevenfold) than that of the first, which again suggests a denaturation process, especially in the light of the absence of concentration-dependence for this part of the transition.

The displacement between the two dissociation curves of L55P was equal to 230 bar, a value very close to the expected value for a monomerto-tetramer association process (300 bar, see equation (4)). The expected $\Delta V$ (equation (4)) is $570 \mathrm{ml} / \mathrm{mol}$, a value $20-30 \%$ larger than that obtained $(430( \pm 30) \mathrm{ml} / \mathrm{mol})$.

The acid-induced dissociation-denaturation curve for L55P monitored by the changes in tryptophan fluorescence intensity also presented two transitions. ${ }^{35}$ The first transition presented concentration-dependence and was attributed to quaternary and tertiary structural changes that lead to the formation of the amyloidogenic state. On lowering the $\mathrm{pH}$ to 3.5-2.5, a second transition took place, which was attributed to the conversion of the amyloidogenic form into a molten-globule state. ${ }^{44}$

Recently, Niraula and co-workers calculated the volume changes for the unfolding of the wt and V30M at $\mathrm{pH} 7.1,4$ or $37^{\circ} \mathrm{C}$ by the use of highpressure NMR spectroscopy. ${ }^{33}$ The values obtained at $4{ }^{\circ} \mathrm{C}$ were around $-200 \mathrm{ml} / \mathrm{mol}$ for the dissociation-unfolding of both wt and V30M. The value calculated here for the dissociation of L55P as followed by fluorescence spectroscopy was much higher $(-430 \mathrm{ml} / \mathrm{mol})$ than that reported for the wt or V30M. When we calculated the volume change for the dissociation of V30M and wt TTR by using the data presented in Figure 1 $\left(1^{\circ} \mathrm{C}\right)$, we found $-200 \mathrm{ml} / \mathrm{mol}$ and $-250 \mathrm{ml} / \mathrm{mol}$, respectively, in excellent agreement with the NMR studies. It would be interesting to verify by NMR spectroscopy whether the change in volume for the dissociation-unfolding of L55P would match with ours.

Recently, Liu and co-workers performed deuterium-proton exchange NMR experiments at $\mathrm{pH} 7$ and determined that the stable core of TTR composed of strands A, B, E and G, and the loop between $A$ and $B$ is destabilized in the V30M and L55P mutants. ${ }^{44}$ This study revealed the high level of structural plasticity displayed by the L55P in relation to the other variants of TTR. Indeed, the observed amide-exchange rates were similar in V30M, wt and T119M but much more prominent in L55P. Probably, the structural plasticity displayed by L55P would create a higher content of cavities in its core, which could explain the observed higher volume change of association described here. High pressure provides a remarkable way to evaluate the relation between dynamics and stability, especially because of the direct relation between protein flexibility (due to volume fluctuations) and its isothermal compressibility. ${ }^{28}$

\section{“Sick fold” induced by HHP}

When wt TTR is subjected to two consecutive cycles of compression, an altered tetramer $\left(\mathrm{T}_{4}^{*}\right)$, with lower pressure stability, is formed. ${ }^{22}$ It can be observed in Figure 6 that wt TTR dissociates at lower pressures in the second cycle of compression, indicating that $\mathrm{T}_{4}^{*}$ is less stable than the native $\mathrm{T}_{4}$ TTR (Figure 6 , circles). At $1{ }^{\circ} \mathrm{C}$, the $\mathrm{T}_{4}^{*}$ species does not aggregate. At $37^{\circ} \mathrm{C}$, aggregation takes place rapidly after decompression (Figure 3 ).

Previous studies with L55P reported that this variant exists in an amyloidogenic conformation, aggregating under certain conditions in which the wt protein remains stable and non-amyloidogenic. ${ }^{45}$ Figure $6(\mathrm{~A})$ compares the extent of reaction $(\alpha)$ as a function of pressure for the wt and L55P. The open and filled circles represent the first and second cycle of compression of the wt protein, respectively, at $\mathrm{pH} 5.6$ and $1{ }^{\circ} \mathrm{C}$. The second decompression curve is presented as a dotted line. The triangles represent the first cycle of compression of $\mathrm{L} 55 \mathrm{P}$ at $\mathrm{pH} 7.5,1^{\circ} \mathrm{C}$. It is interesting to note that consecutive cycles of HHP progressively convert the wt protein into a "L55P-like protein" in terms of pressure stability as well as amyloidogenic properties (Figures 3 and 6(A)). The second cycle of compression of the wt protein is closer to the compression curve of L55P, while the wt decompression curve overlaps with the L55P compression curve. It is possible that the conformation of $\mathrm{T}_{4}^{*}$ observed for the wt TTR, which has a large hydrophobic segment exposed to the solvent as measured by bis-ANS binding, ${ }^{22}$ could resemble the native, amyloidogenic conformation of L55P that undergoes aggregation at much milder $\mathrm{pH}$ values.

Figure $6(\mathrm{~B})$ shows the $p_{1 / 2}$ values at $1^{\circ} \mathrm{C}$ for all the mutants studied thus far, as well as the values found for the first and second compression curves, and for the decompression curve of the wt protein. From these data it is clear that pressure is promoting irreversible structural modifications in the wt protein, converting its native fold into a "defective fold" that is already present in L55P under physiological conditions ( $\mathrm{pH}$ 7.5).

By the use of NMR ${ }^{2} \mathrm{H}-\mathrm{H}$ exchange experiments, Liu and co-workers observed that at $\mathrm{pH} 4.5$ there is a selective destabilization of one-half of the $\beta$-sandwich structure of TTR where the hydrogen bonds connecting $\beta$ strands $C$ to $B, B$ to $E$ and $E$ to $F$ are destabilized. ${ }^{46}$ It is possible that HHP is disrupting 

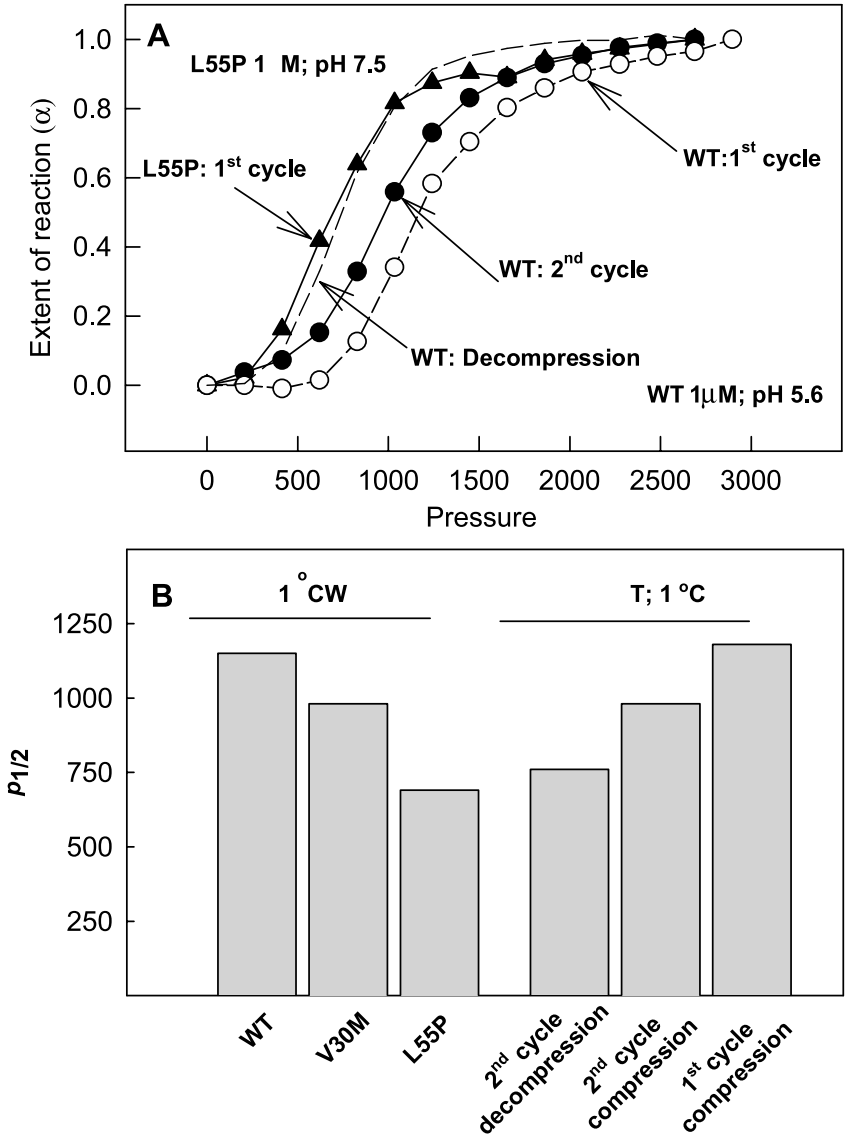

Figure 6. Pressure induces a "sick" fold in wt TTR. (A) Extent of reaction as a function of pressure for the first $(O)$ and second cycles of compression and decompression (- -) of the wt TTR at $\mathrm{pH}$ $5.6,1^{\circ} \mathrm{C}$ as well as the first cycle of compression of L55P at $\mathrm{pH} 7.5$ and $1{ }^{\circ} \mathrm{C}(\boldsymbol{\Delta})$. (B) Bar graph showing the $p_{1 / 2}$ values for the dissociationdenaturation of TTR wt and variants at $1{ }^{\circ} \mathrm{C}$. The $p_{1 / 2}$ values observed for the consecutive cycles of compression-decompression of the wt protein are shown on the right. Note that, as the wt protein is subjected to consecutive cycles of compression-decompression, its $p_{1 / 2}$ values approach the value shown for L55P. the same half of the molecule that is destabilized by acidic $\mathrm{pH}$.

From the data presented up to this point combined with previous data from the literature, we propose the following cycle of reactions for TTR:

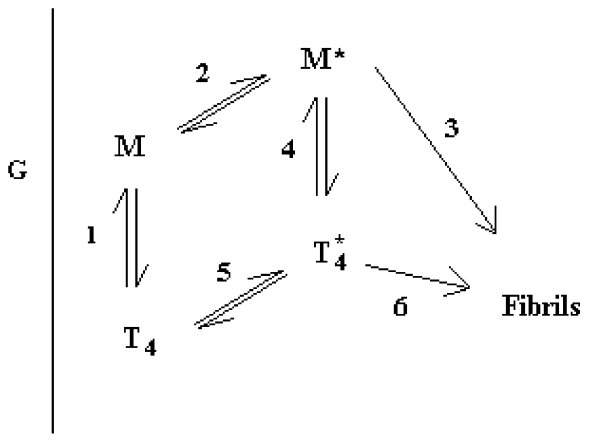

It is not possible to conclude from our experiments whether $\mathrm{T}_{4}^{*}$ itself is able to form fibrils (pathway 6) or whether amyloidogenesis proceeds through $\mathrm{M}^{*}$, derived from $\mathrm{T}_{4}^{*}$ (pathways $4+3$ ). This may happen because $\mathrm{T}_{4}^{*}$ is a much weaker tetramer and it may first dissociate into monomers followed by aggregation. HHP shifts the above equilibrium to any species with altered conformation (* species) that has propensity for fibril formation.

Concerning the above equilibrium for wt TTR, reactions 1,2, 3 or 5 are strongly shifted to the left $\left(\mathrm{T}_{4}\right)$. However, after the first cycle of compression, the altered tetrameric species $\left(\mathrm{T}_{4}^{*}\right)$ is formed and aggregation takes place by either pathways $4+3$ or by pathway 6 . Thus, HHP shifts the equilibria to the right, favoring fibril formation. Acidic $\mathrm{pH}$ $(<5)$ drives the equilibrium to the amyloidogenic conformation rendering the $\mathrm{wt}$ protein amyloidogenic.

In the case of L55P, reactions $1+2$ or 5 are displaced to the right even at higher $\mathrm{pH}$ (e.g. 5.6) favoring $\mathrm{M}^{*}$ and $\mathrm{T}_{4}^{*}$ species and aggregation occurs easily. HHP helps, since it forces the equilibrium even more to the right, either by promoting the formation of a weaker tetramer or by promoting a small population of monomers that funnels to the aggregation pathways (6 or 3). Therefore, it seems plausible that HHP poisons the above equilibria to the direction of fibril formation.

The higher stability of the non-amyloidogenic variant T119M can be understood in the light of recent structural studies. ${ }^{47}$ The T119M substitution can increase the stability because of the formation of new H-bonds within and between monomer contacts (e.g. Ser117-Ser117 and Met119-Tyr114) as well as by inducing a conformational change that leads to a closer contact between different dimers in the tetramer. Hydrogen bonds are little affected by pressure. ${ }^{28}$

In addition, the stabilizing effect of glucose could be explained if we assume that the sugar shifts reactions 1 and 5 in the direction of $T_{4}$, impeding the formation of either $\mathrm{T}_{4}^{*}$ or $\mathrm{M}^{*}$. In the case of $\mathrm{A} \beta$ peptide, Yang and collaborators have 


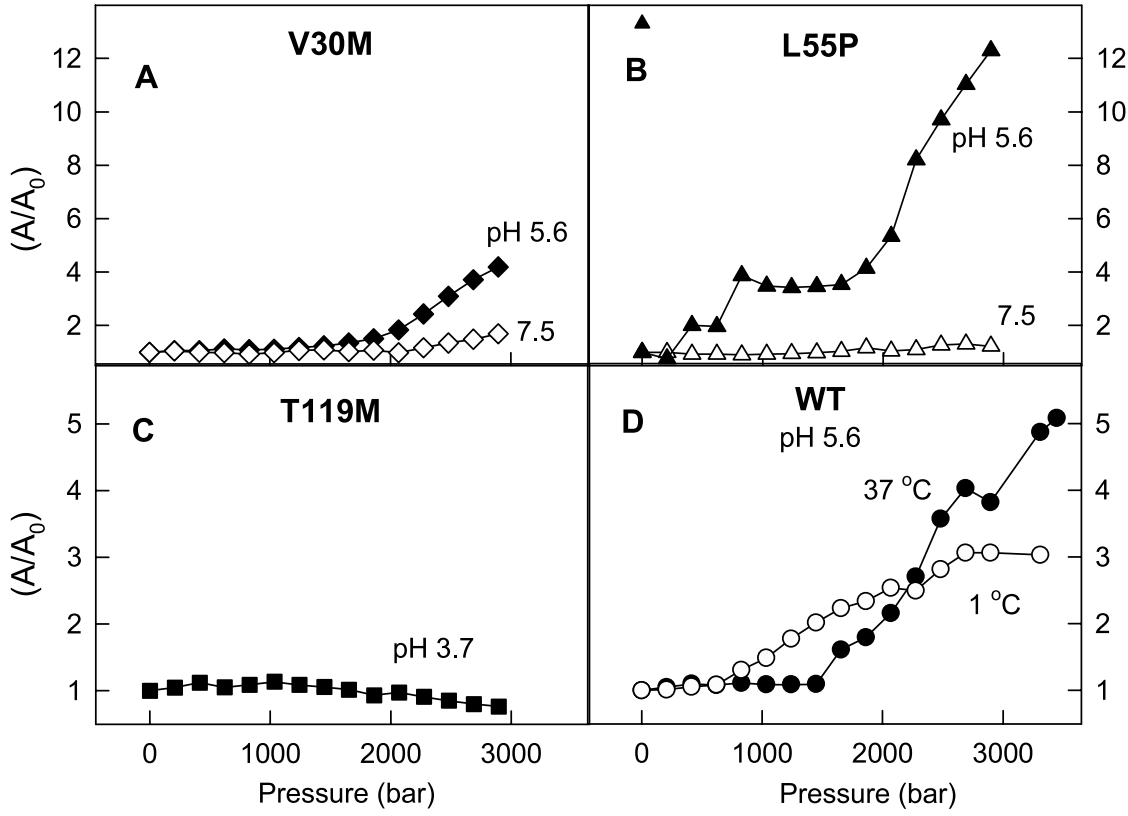

Figure 7. Persistence of tertiary contacts in the species of TTR trapped under HHP as measured by bis-ANS binding. (A) V30M $(1 \mu \mathrm{M})$ at $37^{\circ} \mathrm{C}$ was compressed at $\mathrm{pH} 5.6(\diamond)$ or $7.5(\diamond)$ in the presence of $10 \mu \mathrm{M}$ bis-ANS. The same conditions were used for L55P (B). The experiment with T119M was performed at $37^{\circ} \mathrm{C}$ and pH 3.7 (C). In (D), $1 \mu \mathrm{M}$ wt TTR was compressed at $\mathrm{pH} 5.6$ in the presence of $10 \mu \mathrm{M}$ bis-ANS at $1(\mathrm{O})$ or $37^{\circ} \mathrm{C}(\bullet)$. The spectra were collected from samples excited at $360 \mathrm{~nm}$ and scanning the emission in the region between $400 \mathrm{~nm}$ and $600 \mathrm{~nm}$. The area of each bis-ANS spectrum was divided by the initial area at atmospheric pressure $\left(A / A_{0}\right)$. The isolated symbol in the left of $B$ represents the bis-ANS binding after decompression. shown that trimethylamine n-oxide (TMAO) and glycerol enhanced the random coil to $\beta$-sheet transition, thus favoring aggregation. ${ }^{39}$ Since osmolytes act to maintain the correctly folded proteins, we can assume that glucose stabilizes the native, $\beta$-sheet rich species of TTR as well as the $\beta$-sheet $\mathrm{A} \beta$ peptide. While the former is non-amyloidogenic, the latter is highly amyloidogenic.

\section{Characterizing the conformational state of TTR trapped under pressure}

The high-pressure denatured state of wt TTR binds bis-ANS, indicating the persistence of some tertiary contacts. ${ }^{22}$ However, the extent of bis-ANS binding is related to $\mathrm{pH}$ : at $\mathrm{pH} 7.5$ the binding is negligible, while at more acidic $\mathrm{pH}$ (5 and 5.6) the binding is much more pronounced. ${ }^{22}$ Curiously, the extent of aggregation after HHP is correlated with $\mathrm{pH}$, being more intense at acidic $\mathrm{pH}$ and absent at neutral $\mathrm{pH}$.

To investigate whether the species of TTR variants trapped under HHP retain residual tertiary structure, bis-ANS binding was measured during compression: Figure $7(\mathrm{~A})$ shows the extent of bisANS binding to $\mathrm{V} 30 \mathrm{M}$ at $37^{\circ} \mathrm{C}$ and $\mathrm{pH} 5.6$ or 7.5 . As seen, binding was more pronounced at $\mathrm{pH}$ 5.6, suggesting that the species formed under pressure are different at these two $\mathrm{pH}$ values in spite of the fact that tryptophan emission shifts to the same final value $\left(\sim 28,850 \mathrm{~cm}^{-1}\right)$. Figure $7(B)$ shows the same behavior for L55P, whereas in Figure 7(C), T199M does not bind bis-ANS even at very acidic $\mathrm{pH}$. In fact, T119M never aggregated under any condition, and at $\mathrm{pH} 3.7$ and $37^{\circ} \mathrm{C}$, its center of spectral mass shifted to $29,000 \mathrm{~cm}^{-1}$ at $3000 \mathrm{bar}$ (Figure 4(A)), suggesting extensive exposure of tryptophan residues to the aqueous environment.
Therefore, although tryptophan emission shifted almost entirely to the red when T119M was subjected to high pressure at $\mathrm{pH} 3.7$, there was no detectable bis-ANS binding. We emphasize the contrast with L55P at $\mathrm{pH}$ 5.6, where the spectral area of the probe increased 12-fold upon compression (Figure 7(B)).

These data suggest that, although the tryptophan residues are equally exposed to the solvent under pressure either at $\mathrm{pH} 5.6$ or 7.5 , other regions of the protein appear not to respond similarly to $\mathrm{HHP}$ treatment at these two $\mathrm{pH}$ values. Likely, at acidic $\mathrm{pH}$, there are regions of the protein that are more affected by high pressure, being responsible for the inter species contacts and fibrillogenesis.

Figure 7(D) shows two binding curves performed with wt protein at $1{ }^{\circ} \mathrm{C}$ and $37^{\circ} \mathrm{C}$. The extent of binding was less pronounced at $1^{\circ} \mathrm{C}$, suggesting that the partially folded state trapped under pressure is destabilized at $1{ }^{\circ} \mathrm{C}$.

Taken together, our results show that the wt and amyloidogenic variants of TTR are dissociated and denatured by HHP into a conformation that retains some structure, as measured by bis-ANS binding, probably a molten globule conformation. From these data we can conclude that there is a direct correlation between the extent of bis-ANS binding under pressure and extent of aggregation after decompression: at low $\mathrm{pH}$ values, bis-ANS binding is more pronounced, and so is aggregation. Therefore, it seems that TTR has to experience this partially folded state under pressure in order to undergo aggregation after decompression.

It is important to emphasize that after decompression under all conditions, bis-ANS emission remained high, suggesting persistence of nonnative contacts (see the isolated symbol at the upper left in Figure 7(B) as an example). 


\section{Conclusions}

Our data suggest that HHP induces a defective fold in wt TTR, mimicking the structural effects of the natural mutations. In contrast, glucose decreases fibril propensity by avoiding the formation of the amyloidogenic conformation and by stabilizing the tetramers. The defective fold, present in the tetramer recovered after a cycle of compression-decompression, exhibits a lower thermodynamic stability when compared to native, non-compressed tetramer, but similar to that of L55P. On the other hand, under aggregating conditions, wt and mutants assume an amyloidogenic state, giving rise to fibrils after decompression. This means that HHP shifts the equilibrium between the native conformation and the amyloidogenic ones (either the defective tetramer or a monomer derived from it) to the right, favoring aggregation.

The larger volume change observed for L55P variant demonstrates that amyloidogenesis correlates with less packed structures (larger volume changes) and high susceptibility to water infiltration. Experimental and theoretical approaches indicate that the underlying mechanism of pressure unfolding is the penetration of water into the protein matrix. ${ }^{35-37}$ The diffraction pattern of several amyloids seems to indicate that amyloid fibers are water-filled nanotubes. ${ }^{48}$ However, the protein-protein interactions either in the tetramer or in the fiber exclude water. Thus, hydration plays a crucial role both in the dissociation of the tetramers and in the amyloidogenic process.

\section{Materials and Methods}

\section{Chemicals}

All reagents were of analytical grade. Bis-(8-anilinonaphthalene-1-sulfonate) (bis-ANS) was purchased from Molecular Probes (Eugene, OR). Distilled water was filtered and deionized through a Milli-Q water purification system (Millipore Corp., Bedford, MA). The highpressure experiments were performed in the following buffers: $50 \mathrm{mM}$ Mes (pH 5.0 or 5.6), $100 \mathrm{mM} \mathrm{KCl}$; and $50 \mathrm{mM}$ Tris $-\mathrm{HCl}$ (pH 7.5), $100 \mathrm{mM} \mathrm{KCl}$. When stated, glucose was included in the buffers. We emphasize that Tris and Mes buffers were chosen for pressure experiments because the $\mathrm{pH}$ does not change significantly under high pressure. The $\Delta V$ values for the protonic ionization of Mes and Tris are positive and equal 3.9 and $4.3 \mathrm{~cm}^{3} / \mathrm{mol}$, respectively. ${ }^{49}$

\section{Protein purification}

Recombinant TTR was expressed and purified as described. $^{50}$ Protein concentration was determined using an extinction coefficient of $7.76 \times 10^{4} \mathrm{M}^{-1} \mathrm{~cm}^{-1}$ at $280 \mathrm{~nm}^{3}$

\section{Spectroscopic measurements under pressure}

The high-pressure cell equipped with optical windows has been described ${ }^{43}$ and was purchased from ISS (Champaign, IL). Fluorescence spectra were recorded on an ISS K2 spectrofluorometer (ISS Inc., Champaign, IL). The pressure was increased in steps of 200 bar. At each step, the sample was allowed to equilibrate for 15 minutes prior to making measurements. There were no time-dependent changes in fluorescence spectra between ten and 60 minutes. Tryptophan emission spectra were obtained by setting the excitation at $280 \mathrm{~nm}$ and collecting the emission in the 300-400 $\mathrm{nm}$ range. The bis-ANS spectra were recorded by exciting the sample at $360 \mathrm{~nm}$ and collecting emission from $400 \mathrm{~nm}$ to $600 \mathrm{~nm}$. The mean energy of the fluorescence emission at pressure $p$ evaluated by the center of spectral mass $\left\langle v_{p}\right\rangle$ :

$$
\left\langle v_{p}\right\rangle=\sum v_{\mathrm{i}} F_{\mathrm{i}} / \sum F_{\mathrm{i}}
$$

where $F_{\mathrm{i}}$ is the fluorescence emitted at wavenumber $v_{\mathrm{i}}{ }^{22,43}$ The degree of dissociation $(\alpha)$ is related to $\left\langle v_{p}\right\rangle$ by the expression:

$$
\alpha=\left(\left\langle v_{p}\right\rangle-\left\langle v_{\mathrm{i}}\right\rangle\right) /\left(\left\langle v_{\mathrm{i}}\right\rangle-\left\langle v_{\mathrm{f}}\right\rangle\right)
$$

where $\left\langle v_{\mathrm{i}}\right\rangle$ and $\left\langle v_{\mathrm{f}}\right\rangle$ are the initial and final values of center of spectral mass, respectively, while $\left\langle v_{p}\right\rangle$ is the center of spectral mass at pressure $p$.

All experiments were performed at least twice using different batches of protein and a representative result is shown.

\section{Thermodynamic parameters}

The standard volume change of association $\Delta V$ and the equilibrium dissociation constant $K_{\mathrm{d}}$ for pressure dissociation extrapolated to atmospheric pressure were determined from the following thermodynamic relation:

$$
\ln \left[\left(\alpha_{p}\right)^{4} /\left(1-\alpha_{p}\right)\right]=p(\Delta V / R T)+\ln \left(K_{\mathrm{d}} / 256 C^{3}\right)
$$

This equation permits the calculation of the standard volume change $\Delta V$ for a tetramer $\leftrightarrow$ monomer equilibrium, from measurements at a fixed protein concentration $C$, at different pressures. A change in protein concentration from $C_{1}$ to $C_{2}$ at a fixed pressure results in a parallel displacement $\Delta p$ of the plot $\ln \left[\left(\alpha_{p}\right)^{4} /\left(1-\alpha_{p}\right)\right]$ versus $p$. At $50 \%$ dissociation, this shift $\left(\Delta p_{1 / 2}\right)$ in pressure upon change in concentration is given by the following equation: ${ }^{42}$

$$
\Delta p_{1 / 2}=(n-1)(R T / \Delta V) \ln \left(C_{2} / C_{1}\right)
$$

\section{Aggregation measurements and fibril formation}

The extent of aggregation was evaluated by the lightscattering (LS) observed on exciting the samples at $320 \mathrm{~nm}$ and collecting the light at $90^{\circ}$ through the monochromator $(315-325 \mathrm{~nm})$. Since aggregation was performed inside the high-pressure cell, the samples were not stirred. Thioflavin $\mathrm{T}(5 \mu \mathrm{M})$ was also used as an indicator of the presence of fibrils. In this case, the sample was excited at $440 \mathrm{~nm}$ and emission collected at $482 \mathrm{~nm}$ after decompression. 


\section{Acknowledgements}

We are grateful to Martha M. Sorenson for critical reading of the manuscript and Emerson R. Gonçalves for competent technical assistance. This work was supported, in part, by grants from Conselho Nacional de Desenvolvimento Científico e Tecnológico $(\mathrm{CNPq})$, Programa de Núcleos de Excelência (PRONEX), Fundação de Amparo à Pesquisa no Estado do Rio de Janeiro (FAPERJ) of Brazil to D.F. and J.L.S, by an international grant from the Howard Hughes Medical Institute to J.L.S., and by U.S. Public Health Service Grant from the National Institutes of Health to J.W.K.

\section{References}

1. Rochet, J. C. \& Lansbury, P. T., Jr (2000). Amyloid fibrillogenesis: themes and variations. Curr. Opin. Struct. Biol. 10, 60-68.

2. Wetzel, R. (1996). For protein misassembly, it's the "I" decade. Cell, 86, 699-702.

3. Radford, S. E. \& Dobson, C. M. (1999). From computer simulations to human disease: emerging themes in protein folding. Cell, 97, 291-298.

4. Kelly, J. W. (2002). Towards an understanding of amyloidogenesis. Nature Struct. Biol. 9, 323-325.

5. Blake, C. C., Geisow, M. J., Swan, I. D., Rerat, C. \& Rerat, B. (1974). Structure of human plasma prealbumin at $2-5 \AA$ resolution. A preliminary report on the polypeptide chain conformation, quaternary structure and thyroxine binding. J. Mol. Biol. 88, $1-12$.

6. Blake, C. C., Geisow, M. J., Oatley, S. J., Rerat, B. \& Rerat, C. (1978). Structure of prealbumin: secondary, tertiary and quaternary interactions determined by Fourier refinement at 1.8 A. J. Mol. Biol. 121, 339-356.

7. Van Jaarsveld, P., Branch, W. T., Robbins, J., Morgan, F. J., Kanda, Y. \& Canfield, R. E. (1973). Polymorphism of Rhesus monkey serum prealbumin. Purification and partial structure. J. Biol. Chem. 248, 7898-7903.

8. Rosen, H. N., Moses, A. C., Murell, J., Liepnieks, J. J. \& Benson, M. D. (1993). Thyroxine interactions with transthyretin: a comparison of 10 different naturally occurring human transthyretin variants. J. Clin. Endocrinol. Metab. 77, 370-374.

9. Westermark, P., Sletten, K., Johansson, B. \& Cornwell, G. G. (1990). Fibril in senile systemic amyloidosis is derived from normal transthyretin. Proc. Natl Acad. Sci. USA, 87, 2843-2845.

10. Saraiva, M. J., Birken, S., Costa, P. P. \& Goodman, D. S. (1984). Amyloid fibril protein in familial amyloidotic polyneuropathy, Portuguese type. Definition of molecular abnormality in transthyretin (prealbumin). J. Clin. Invest. 74, 104-119.

11. Benson, M. D. (1989). Familial amyloidotic polyneuropathy. Trends Neurosci. 12, 88-92.

12. Coelho, T. (1996). Familial amyloid polyneuropathy: new developments in genetics and treatment. Curr. Opin. Neurol. 9, 355-359.

13. Longo-Alves, I., Hays, M. T. \& Saraiva, M. J. (1997). Comparative stability and clearance of [Met30]transthyretin and [Met119]transthyretin. Eur. J. Biochem. 249, 662-668.

14. Hammarstrom, P., Schneider, F. \& Kelly, J. W. (2001).
Trans-suppression of misfolding in an amyloid disease. Science, 293, 2459-2461.

15. Hornberg, A., Eneqvist, T., Olofsson, A., Lundgren, E. \& Sauer-Eriksson, A. E. (2000). A comparative analysis of 23 structures of the amyloidogenic protein transthyretin. J. Mol. Biol. 302, 649-669.

16. Damas, A. M. \& Saraiva, M. J. (2000). Review: TTR amyloidosis-structural features leading to protein aggregation and their implications on therapeutic strategies. J. Struct. Biol. 130, 290-299.

17. McCutchen, S. L., Kelly, J. W. \& Colon, W. (1993). Transthyretin mutation Leu-55-Pro significantly alters tetramer stability and increases amyloidogenicity. Biochemistry, 32, 12119-12127.

18. McCutchen, S. L., Lai, Z., Miroy, G., Kelly, J. W. \& Colon, W. (1995). Comparison of lethal and nonlethal transthyretin variants and their relationship to amyloid disease. Biochemistry, 34, 13527-13536.

19. Lashuel, H. A., Lai, Z. \& Kelly, J. W. (1998). Characterization of the transthyretin acid denaturation pathways by analytical ultracentrifugation: implications for wild-type, V30M, and L55P amyloid fibril formation. Biochemistry, 37, 17851-17864.

20. Quintas, A., Saraiva, M. J. \& Brito, R. M. M. (1999). The tetrameric protein transthyretin dissociates to a non-native monomer in solution. A novel model for amyloidogenesis. J. Biol. Chem. 274, 32943-32949.

21. Kelly, J. W. (1998). The alternative conformations of amyloidogenic proteins and their multi-step assembly pathways. Curr. Opin. Struct. Biol. 8, 101-106.

22. Ferrão-Gonzales, A. D., Souto, S. O., Silva, J. L. \& Foguel, D. (2000). The preaggregated state of an amyloidogenic protein: hydrostatic pressure converts native transthyretin into the amyloidogenic state. Proc. Natl Acad. Sci. USA, 97, 6445-6450.

23. Serag, A. A., Altenbach, C., Gingery, M., Hubbell, W. L. \& Yeates, T. O. (2001). Identification of a subunit interface in transthyretin amyloid fibrils: evidence for self-assembly from oligomeric building blocks. Biochemistry, 40, 9089-9096.

24. Olofsson, A., Ippel, H. J., Baranov, V., Horstedt, P., Wijmenga, S. \& Lundgren, E. (2001). Capture of a dimeric intermediate during transthyretin amyloid formation. J. Biol. Chem. 43, 39592-39599.

25. Eneqvist, T., Andersson, K., Olofsson, A., Lundgren, E. \& Sauer-Eriksson, A. E. (2000). The beta-slip: a novel concept in transthyretin amyloidosis. Mol. Cell, 6, 1207-1218.

26. Redondo, C., Damas, A. M. \& Saraiva, M. J. (2000). Designing transthyretin mutants affecting tetrameric structure: implications in amyloidogenicity. Biochem. J. 348, 167-172.

27. Jonas, J. \& Jonas, A. (1994). High-pressure NMR spectroscopy of proteins and membranes. Annu. Rev. Biophys. Biomol. Struct. 23, 287-318.

28. Silva, J. L., Foguel, D. \& Royer, C. A. (2001). Pressure provides new insights into protein folding, dynamics and structure. Trends Biochem. Sci. 26, 612-618.

29. Gorovits, B. M. \& Horowitz, P. M. (1998). High hydrostatic pressure can reverse aggregation of protein folding intermediates and facilitate acquisition of native structure. Biochemistry, 37, 6132-6135.

30. Foguel, D., Robinson, C. R., deSousa, P. C., Jr, Silva, J. L. \& Robinson, A. S. (1999). Hydrostatic pressure rescues native protein from aggregates. Biotechnol. Bioeng. 63, 552-558.

31. St John, R. J., Carpenter, J. F. \& Randolph, T. W. (1999). High pressure fosters protein refolding from 
aggregates at high concentrations. Proc. Natl Acad. Sci. USA, 96, 13029-13033.

32. Meersman, F., Smeller, L. \& Heremans, K. (2002). Comparative Fourier transform infrared spectroscopy study of cold-, pressure-, and heat-induced unfolding and aggregation of myoglobin. Biophys. J. $82,2635-2644$.

33. Niraula, T. N., Haraoka, K., Ando, Y., Li, H., Yamada, H. \& Akasaka, K. (2002). Decreased thermodynamic stability as a crucial factor for familial amyloidotic polyneuropathy. J. Mol. Biol. 320, 333-342.

34. Schneider, F., Hammarstrom, P. \& Kelly, J. W. (2001). Transthyretin slowly exchanges subunits under physiological conditions: a convenient chromatographic method to study subunit exchange in oligomeric proteins. Protein Sci. 10, 1606-1613.

35. Hummer, G., Garde, S., Garcia, A. E., Paulaitis, M. E. \& Pratt, L. R. (1998). The pressure dependence of hydrophobic interactions is consistent with the observed pressure denaturation of proteins. Proc. Natl Acad. Sci. USA, 95, 1552-1555.

36. Hillson, N., Onuchic, J. N. \& Garcia, A. E. (1999). Pressure-induced protein-folding/unfolding kinetics. Proc. Natl Acad. Sci. USA, 96, 14848-14853.

37. Oliveira, A. C., Gaspar, L. P., Da Poian, A. T. \& Silva, J. L. (1994). Arc repressor will not denature under pressure in the absence of water. J. Mol. Biol. 240, 184-187.

38. Timasheff, S. N. (2002). Protein-solvent preferential interactions, protein hydration, and the modulation of biochemical reactions by solvent components. Proc. Natl Acad. Sci. USA, 99, 9721-9726.

39. Yang, D. S., Yip, C. M., Huang, T. H., Chakrabartty, A. \& Fraser, P. E. (1999). Manipulating the amyloidbeta aggregation pathway with chemical chaperones. J. Biol. Chem. 274, 32970-32974.

40. Scheibel, T. \& Lindquist, S. L. (2001). The role of conformational flexibility in prion propagation and maintenance for Sup35p. Nature Struct. Biol. 8, 958-962.
41. McCutchen, S. L., Lai, Z., Miroy, G. J., Kelly, J. W. \& Colon, W. (1995). Comparison of lethal and nonlethal transthyretin variants and their relationship to amyloid disease. Biochemistry, 34, 13527-13536.

42. Silva, J. L. \& Weber, G. (1993). Pressure stability of proteins. Annu. Rev. Phys. Chem. 44, 89-113.

43. Silva, J. L., Villas-Boas, M., Bonafe, C. F. \& Meirelles, N. C. (1989). Anomalous pressure dissociation of large protein aggregates. Lack of concentration dependence and irreversibility at extreme degrees of dissociation of extracellular hemoglobin. J. Biol. Chem. 264, 15863-15868.

44. Liu, K., Kelly, J. W. \& Wemmer, D. E. (2002). Native state hydrogen exchange study of suppressor and pathogenic variants of transthyretin. J. Mol. Biol. 320, 821-832.

45. Lashuel, H. A., Wurth, C., Woo, L. \& Kelly, J. W. (1999). The most pathogenic transthyretin variant, L55P, forms amyloid fibrils under acidic conditions and protofilaments under physiological conditions. Biochemistry, 38, 13560-13573.

46. Liu, K., Cho, H. S., Lashuel, H. A., Kelly, J. W. \& Wemmer, D. E. (2000). A glimpse of a possible amyloidogenic intermediate of transthyretin. Nature Struct. Biol. 7, 754-757.

47. Sebastiao, M. P., Lamzin, V., Saraiva, M. J. \& Damas, A. M. (2001). Transthyretin stability as a key factor in amyloidogenesis: X-ray analysis at atomic resolution. J. Mol. Biol. 306, 733-744.

48. Perutz, M. F., Finch, J. T., Berriman, J. \& Lesk, A. (2002). Amyloid fibers are water-filled nanotubes. Proc. Natl Acad. Sci. USA, 99, 5591-5595.

49. Kitamura, Y. \& Itoh, T. (1987). Reaction volume of protonic ionization for buffering agent. Prediction of pressure dependence of $\mathrm{pH}$ and $\mathrm{pOH}$. J. Solution Chem. 16, 715-727.

50. Lai, Z., Colon, W. \& Kelly, J. W. (1996). The acidmediated denaturation pathway of transthyretin yields a conformational intermediate that can selfassemble into amyloid. Biochemistry, 35, 6470-6482.

Edited by P. T. Lansbury Jr 